\title{
Early experience of an infectious and tropical diseases unit during the coronavirus disease (COVID-19) pandemic, Florence, Italy, February to March 2020
}

Filippo Lagi ${ }^{1,2}$, Matteo Piccica ${ }^{1}$, Lucia Graziani ${ }^{1}$, lacopo Vellere ${ }^{1}$, Annarita Botta ${ }^{1}$, Marta Tilli $^{1}$, Letizia Ottino ${ }^{1}$, Beatrice Borchi ${ }^{2}$,

Marco Pozzi ${ }^{2}$, Filippo Bartalesi ${ }^{2}$, Jessica Mencarini $i^{1,2}$, Michele Spinicci $i^{1,2}$, Lorenzo Zammarchi ${ }^{1,2}$, Filippo Pieralli ${ }^{3}$, Giovanni Zagli ${ }^{4}$, Carlo Nozzoli ${ }^{5}$, Stefano Romagnoli ${ }^{4,6}$, Alessandro Bartoloni ${ }^{1,2}$, the COCORA working group ${ }^{7}$

1. Department of Experimental and Clinical Medicine, University of Florence, Florence, Italy

2. Infectious and Tropical Diseases Unit, Azienda Ospedaliero-Universitaria Careggi, Florence, Italy

3. Intermediate Care Unit, Azienda Ospedaliero-Universitaria Careggi, Florence, Italy

4. Department of Anesthesiology and Intensive Care, Azienda Ospedaliero-Universitaria Careggi, Florence, Italy

5. Department of Internal Medicine, Azienda Ospedaliero-Universitaria Careggi, Florence, Italy

6. Health Sciences Department, Section of Anesthesiology, Intensive Care and Pain Medicine - University of Florence, Florence, Italy

7. The members of the COCORA working group are listed at the end of the article

Correspondence: Lorenzo Zammarchi (Lorenzo.Zammarchi@unifi.it)

Citation style for this article:

Lagi Filippo, Piccica Matteo, Graziani Lucia, Vellere Iacopo, Botta Annarita, Tilli Marta, Ottino Letizia, Borchi Beatrice , Pozzi Marco, Bartalesi Filippo, Mencarini Jessica, Spinicci Michele, Zammarchi Lorenzo, Pieralli Filippo, Zagli Giovanni, Nozzoli Carlo, Romagnoli Stefano, Bartoloni Alessandro, the COCORA working group. Early experience of an infectious and tropical diseases unit during the coronavirus disease (COVID-19) pandemic, Florence, Italy, February to March 2020. Euro Surveill. 2020;25(17): pii=2000556. https://doi.org/10.2807/1560-7917.ES.2020.25.17.2000556

We analysed the first 84 coronavirus disease (COVID19) patients hospitalised in an infectious and tropical disease unit in Florence, Italy, over 30 days after the start of the COVID-19 outbreak in Italy. A $12 \%$ reduction in the rate of intensive care unit transfer was observed after the implementation of intensity care measures in the regular ward such as increasing the nurse/patient ratio, presence of critical care physicians and using high flow nasal cannulae oxygenation.

Since the first case reported on 21 February 2020 in Lombardia region, Italy has become one of the countries most affected by the coronavirus disease (COVID19) pandemic, counting more than 197,000 cases and more than 26,000 fatalities by 27 April. At the end of April, Italy has the highest numbers of confirmed deaths in Europe [1,2].

We present our first-month experience of the COVID-19 pandemic in Italy at the Infectious and Tropical Disease Unit (ITD) of the University Hospital in Florence, Tuscany. We aimed to describe clinical and demographic characteristics of hospitalised patients with COVID-19 as well as differences between hospitalised patients not transferred to the intensive care unit (ICU) and hospitalised patients later transferred to the ICU. Finally, we analysed the incidence rate of ICU transfers before and after the implementation of additional intensity care measures on our regular ward.

\section{Construction of the cohort and data analysis}

We enrolled all laboratory-confirmed COVID-19 cases who were hospitalised in the ITD ward between 25 February and 26 March 2020. A laboratory-confirmed case was a symptomatic patient with positive result on a reverse-transcriptase (RT)-PCR assay. Demographic and clinical data were collected from electronic medical hospital records. ICU transfer was the primary outcome. Categorical variables were analysed by chisquared or Fisher's exact test and continuous variables by the Kruskal-Wallis test. Poisson regression model was used for regression analysis. Cases were followedup from the first day of hospitalisation to ICU transfer or hospital discharge or death. Cases still hospitalised were censored on 3 April.

Data collection was approved by the local Ethics Committee (17104_0ss). The study was performed in accordance with the ethical principles of the Declaration of Helsinki and with the International Conference on Harmonization Good Clinical Practice guidelines.

\section{Rising intensity of care: pre- and post-intervention}

Since the beginning of the COVID-19 outbreak in Italy, the intensity care level in the ITD was gradually increased. Under standard operations, hereafter referred to as 'pre-intervention', our ward has a nurse-patient ratio of $1: 10$. Thirteen days after hospitalisation of the first COVID-19 case, hereafter referred to as 'post-intervention', the nurse patient ratio was enhanced to $1: 6$, a stable team of critical care physicians was formed, and 
TABLE 1

Clinical and demographic characteristics at admission of hospitalised COVID-19 cases at the infectious and tropical diseases unit of the University Hospital, Florence, Italy, 25 February-26 March $2020(\mathrm{n}=84)^{*}$

\begin{tabular}{|c|c|c|c|c|c|c|c|}
\hline \multirow[t]{2}{*}{ Characteristics } & \multicolumn{2}{|c|}{$\begin{array}{l}\text { Total } \\
(n=84)\end{array}$} & \multicolumn{2}{|c|}{$\begin{array}{c}\text { Not ICU } \\
\text { transferred } \\
(n=68)\end{array}$} & \multicolumn{2}{|c|}{$\begin{array}{l}\text { ICU transferred } \\
\qquad(n=16)\end{array}$} & \multirow[t]{2}{*}{$p$ value } \\
\hline & $n$ & $\%$ or (IQR) & $\mathrm{n}$ & $\%$ or (IQR) & $\mathrm{n}$ & $\%$ or (IQR) & \\
\hline \multicolumn{8}{|l|}{ Age and sex } \\
\hline Age, median (years) & 62 & $(51-72)$ & 62 & $(50-72)$ & 67 & $(58-71)$ & $0.2919^{c}$ \\
\hline Male & 55 & 65.5 & 41 & 60.3 & 14 & 87.5 & \multirow{2}{*}{$0.045^{\mathrm{a}}$} \\
\hline Female & 29 & 34.5 & 27 & 39.7 & 2 & 12.5 & \\
\hline \multicolumn{8}{|l|}{ Smoking } \\
\hline Former smoker & 19 & 22.6 & 12 & 17.6 & 7 & 43.8 & \multirow{4}{*}{$0.025^{\mathrm{a}}$} \\
\hline Smoker & 6 & 7.1 & 5 & 7.3 & 1 & 6.2 & \\
\hline Non-smoker & 46 & 54.8 & 42 & 61.8 & 4 & 25.0 & \\
\hline Unknown & 13 & 15.5 & 9 & 13.2 & 4 & 25.0 & \\
\hline \multicolumn{8}{|l|}{ Underlying conditions } \\
\hline Diabetes mellitus & 12 & $14 \cdot 3$ & 8 & 11.8 & 4 & 25.0 & $0.230^{b}$ \\
\hline COPD & 5 & 5.6 & 2 & 2.9 & 3 & 18.8 & $0.045^{\mathrm{a}}$ \\
\hline Coronary heart disease & 12 & $14 \cdot 3$ & 7 & 10.3 & 5 & 31.3 & $0.046^{\mathrm{a}}$ \\
\hline Hypertension & 31 & 36.9 & 26 & 38.2 & 5 & 31.3 & $0.602 b$ \\
\hline Chronic hepatitis B & 2 & 2.4 & 1 & 1.5 & 1 & 6.3 & $0.347^{\mathrm{a}}$ \\
\hline Cerebrovascular disease & 2 & 2.4 & 2 & 2.9 & o & 0.0 & NA \\
\hline Former or still oncologic diseases & 7 & 8.3 & 6 & 8.8 & 1 & 6.3 & $0.738^{a}$ \\
\hline Chronic renal failure & 3 & 3.6 & 3 & 4.4 & o & 0.0 & NA \\
\hline \multicolumn{8}{|l|}{ Medication at admission } \\
\hline Prior therapy with ACE inhibitor & 15 & 17.9 & 12 & 17.6 & 3 & 18.9 & $1.000^{\mathrm{a}}$ \\
\hline Prior therapy with sartan & 11 & 13.1 & 9 & 13.2 & 2 & 12.5 & $1.000^{\mathrm{a}}$ \\
\hline Median of days from the onset of symptoms to the nasal swab & 6.5 & $(4-9)$ & 7 & $(5-9)$ & 5 & $(3-7.5)$ & $0.0688^{c}$ \\
\hline $\begin{array}{l}\text { History of contact with a confirmed or suspected case in the } \\
\text { previous } 14 \text { days }\end{array}$ & 16 & 19.1 & 13 & 24.5 & 3 & 9.7 & $0.149^{\mathrm{a}}$ \\
\hline Horowitz index at the baseline, median & 324 & $(281-360)$ & 332 & $(300-364)$ & 280 & $(234-316)$ & $0.0048^{c}$ \\
\hline Radiologically confirmed pneumonia & 73 & 86.9 & 57 & 83.8 & 16 & 100.0 & $0.084^{\mathrm{b}}$ \\
\hline \multicolumn{8}{|l|}{ Medication during hospitalisation } \\
\hline Empiric antibiotic therapy & 44 & 52.4 & 30 & 44.1 & 14 & 87.5 & $0.002^{b}$ \\
\hline Protease inhibitors & 72 & 85.7 & 57 & 83.8 & 15 & 93.8 & $0.307^{b}$ \\
\hline Hydroxychloroquine & 71 & 84.5 & 55 & 80.8 & 16 & 100.0 & $0.057^{b}$ \\
\hline High Flow with Nasal Cannula $24 \mathrm{~h}$ & 9 & 10.7 & 8 & 11.7 & 1 & 6.2 & NA \\
\hline \multicolumn{8}{|l|}{ Outcome at 3 April (data cut off) } \\
\hline Death & 8 & 9.5 & 5 & 7.4 & 3 & 18.8 & \multirow{3}{*}{ NA } \\
\hline Discharged & 57 & 67.9 & 57 & 83.8 & o & 0.0 & \\
\hline Still hospitalised & 19 & 22.6 & 6 & 8.8 & 13 & 81.3 & \\
\hline
\end{tabular}

ACE: angiotensin converting enzyme; COVID-19: coronavirus disease; COPD: chronic obstructive pulmonary disease; ICU: intensive care unit; IQR: interquartile range; NA: not applicable.

a Fisher's exact test.

${ }^{\mathrm{b}}$ chi square test.

' Kruskal-Wallis test.

advanced ventilation support like high flow nasal cannulae oxygenation became available on the ward.

\section{Cohort description}

Overall, we included 84 patients: 16 (19.0\%) were admitted in ICU, while 68 (81.0\%) did not (N-ICU). All ICU patients underwent invasive mechanical ventilation. At the data cut-off date, eight had died (9.5\%), $57^{*}$ were discharged (67.9\%), and 19 (22.6\%) were still hospitalised (six in our unit and 13 in ICU). The median age of cases was 62 years (interquartile range (IQR): $51-72), 55(65.5 \%)$ of cases were males and 49 (58.3\%) had at least one comorbidity. The comorbidities or conditions mainly associated with ICU transfer were having chronic obstructive pulmonary disease (COPD) $(p=0.016)$ and presenting with low Horowitz index $\left(\mathrm{PaO}_{2} / \mathrm{FiO}_{2}\right.$ ratio) at admission $(\mathrm{p}=0.0048)$. All ICU cases had radiologically confirmed pneumonia. 
Laboratory parameters at the admission of hospitalised COVID-19 cases at the infectious and tropical diseases unit of the University Hospital, Florence, Italy, 25 February-26 March $2020(\mathrm{n}=84)^{\star}$

\begin{tabular}{|c|c|c|c|c|c|c|c|c|}
\hline \multirow[t]{2}{*}{ Parameters } & \multirow[t]{2}{*}{$\begin{array}{l}\text { Reference } \\
\text { values }\end{array}$} & \multicolumn{2}{|c|}{$\begin{array}{l}\text { Total } \\
\mathrm{n}=84\end{array}$} & \multicolumn{2}{|c|}{$\begin{array}{c}\text { Not ICU } \\
\text { transferred } \\
n=68\end{array}$} & \multicolumn{2}{|c|}{$\begin{array}{l}\text { ICU transferred } \\
\qquad n=16\end{array}$} & \multirow[t]{2}{*}{$\mathrm{p}$ value } \\
\hline & & Median & IQR & Median & IQR & Median & IQR & \\
\hline $\begin{array}{l}\text { White blood cells } \times 10^{9} / \mathrm{L} \text {, } \\
\text { median }\end{array}$ & $4.00-10.00$ & 5.2 & $4.03-7.5$ & 4.9 & $4.0-5.9$ & 8.3 & $5.1-11.7$ & 0.0028 \\
\hline Neutrophils $\times 10^{9} / \mathrm{L}$ & $1.50-7.50$ & 3.7 & $2.8-5.5$ & 3.4 & $2.6-4.9$ & 6.0 & $4.2-10.2$ & 0.0004 \\
\hline Lymphocytes $10^{9} / \mathrm{L}$ & $0.50-5.00$ & 0.81 & $0.6-1.3$ & 0.83 & $0.7-1.31$ & 0.5 & $0.4-0.9$ & 0.0209 \\
\hline Platlets & $140-440$ & 175 & $145-226$ & 174 & $145-219$ & 195 & $139-255$ & 0.6442 \\
\hline Haemoglobin $\mathrm{g} / \mathrm{dl}$ & $14.0-18.0$ & 13.7 & $11.4-14.8$ & 13.7 & $12.6-14.9$ & 13.6 & $11.3-14.6$ & 0.2364 \\
\hline $\operatorname{ALT}(\mathrm{U} / \mathrm{L})$ & $10-50$ & 24 & $16-44$ & 24 & $15-43$ & 23 & $18-54$ & 0.7074 \\
\hline Creatinine (mg/dL) & $0.70-1.20$ & 0.9 & $0.8-1.1$ & 0.9 & $0.7-1.0$ & 1.0 & $0.8-1.1$ & 0.2389 \\
\hline Sodium $(\mathrm{mEq} / \mathrm{L})$ & $135-145$ & 138 & $136-140$ & 138 & $136-140$ & 137 & $134-139$ & 0.3903 \\
\hline Potassium (mEq/L) & $3.5-5.1$ & 4 & $3.7-4.3$ & 4 & $3.7-4 \cdot 3$ & 3.9 & $3.6-4.3$ & 0.5742 \\
\hline Procalcitonin $(\mathrm{ng} / \mathrm{mL})$ & $<0.5$ & 0.12 & $0.07-0.23$ & 0.09 & $0.06-0.16$ & 0.29 & $0.17-2.07$ & $<0.0001$ \\
\hline $\mathrm{LDH}(\mathrm{U} / \mathrm{L})$ & $135-225$ & 251 & $199-323$ & 239 & $195-284$ & 325 & $259-407$ & 0.0014 \\
\hline IL-6 $(\mathrm{pg} / \mathrm{mL})^{\mathrm{a}}$ & $0.0-10.0$ & 14.7 & $6.8-28.4^{\mathrm{a}}$ & 12.2 & $4.7-26.0^{\mathrm{a}}$ & 48.5 & $17.0-90.7^{\mathrm{a}}$ & $<0.0001$ \\
\hline C-reactive protein (mg/L) & $<5$ & 53 & $24-103$ & 44 & $19-71$ & 126 & $72-209$ & $<0.0001$ \\
\hline
\end{tabular}

ALT: alanine aminotransferase; COVID-19: coronavirus disease; ICU: intensive care unit; IL: interleukin; IQR: interquartile range; LDH: lactate dehydrogenase.

available for 65 patients: 51 not transferred in ICU, 14 transferred in ICU

${ }^{\mathrm{b}}$ Kruskal-Wallis test.

Clinical and demographic characteristics are summarised in Table 1.

Additionally, two women, both in the second trimester of pregnancy, were hospitalised.

Corticosteroid treatment was only prescribed in $\mathrm{N}-\mathrm{ICU}$ patients $(n=14 ; 20.6 \%)$ in the post-intervention period. Overall, three patients received tocilizumab: two in $\mathrm{N}-\mathrm{ICU}$ and one in ICU. Four patients received remdesivir (5.9\%), all in $\mathrm{N}-\mathrm{ICU}$.

\section{Clinical and laboratory characteristics}

Among laboratory parameters at the admission to the ward, we found a higher median of neutrophils and procalcitonin in N-ICU patients. Moreover, a higher median of C-reactive protein was observed in ICU patients compared with N-ICU (126 mg/L (IQR 72-209) and $44 \mathrm{mg} / \mathrm{L}$ (IQR 19-71) respectively; $p<0.0001)$. Although at the admission interleukin- 6 was only available for 65 of 84 patients, we observed a significant difference in the two groups* (Table 2).

We did not find any particular variation in clinical presentation between patients transferred or not to ICU, except for diarrhoea which was more common in the $\mathrm{N}$-ICU group (Table 3). Notably, three patients had an atypical presentation without fever: two syncopes, one abdominal pain. Data on self-reported dysgeusia and anosmia were available only for $48 \mathrm{~N}-\mathrm{ICU}$ of 68 cases, and reported by $54.1 \%$ and $35.4 \%$, respectively.
Clinical characteristics in the preintervention and post-intervention period We observed no difference in age, having COPD, coronary heart disease, chronic hepatitis $B$, cerebrovascular disease, oncologic illness, chronic renal failure, Horowitz index at admission between COVID-19 cases during the pre-intervention or post-intervention phase. The percentage of patients with diabetes mellitus and hypertension was higher at pre-intervention compared with post-intervention ( $25.8 \%$ vs $7.6 \%$ and $58.1 \%$ vs $24.5 \%$ respectively) (Table 4 ).

In the pre- and post-intervention period, nine (29.0\%) and seven (13.2\%) patients were transferred to ICU. The overall rate of ICU transfers in our unit was 2.64 (95\% confidence interval $(\mathrm{Cl}): 1.62-4.31)$ per 100 patient days. The rate of ICU transfers in the postintervention period compared with the pre-intervention period markedly decreased from 6.30 per 100 patient days, (95\% Cl: $3.00-13.22)$ to 1.82 patient days, (95\% $\mathrm{Cl}: 0.94-3.50)$. The unadjusted rate ratio (RR) for transfers for the post-intervention period was 0.28 (95\% Cl: $0.10-0.75 ; p=0.0070)$. After adjustment for sex, age, Horowitz index at baseline, diabetes mellitus, hypertension, COPD, coronary heart disease, the RR for the post-intervention period was 0.88 (95\% Cl: 0.82-0.95; $p=0.002$ ).

\section{Discussion}

The majority of cases hospitalised at ICT during the first 30 days of the COVID-19 pandemic were males older than 60 years of age. More than half of them had at 
Symptoms of hospitalised COVID-19 cases at admission to the infectious and tropical diseases unit of University Hospital, Florence, Italy, 25 February-26 March $2020(\mathrm{n}=84)$

\begin{tabular}{|c|c|c|c|c|c|c|c|}
\hline \multirow[t]{2}{*}{ Symptoms } & \multicolumn{2}{|c|}{$\begin{array}{l}\text { Total } \\
(n=84)\end{array}$} & \multicolumn{2}{|c|}{$\begin{array}{l}\text { Not ICU } \\
\text { transferred } \\
(n=68)\end{array}$} & \multicolumn{2}{|c|}{$\begin{array}{l}\text { ICU transferred } \\
\qquad(n=16)\end{array}$} & \multirow[t]{2}{*}{$p$ value } \\
\hline & $n$ & $\%$ & $\mathrm{n}$ & $\%$ & $\mathrm{n}$ & $\%$ & \\
\hline Fever $>38^{\circ} \mathrm{C}$ & 73 & 86.9 & 59 & 86.8 & 14 & - & $0.937^{c}$ \\
\hline Cough & 59 & 70.2 & 50 & 73.5 & 9 & 56.2 & $0.174^{c}$ \\
\hline Dysgeusia $^{a}$ & 26 & $54.1^{\mathrm{a}}$ & 26 & $54 \cdot 1^{\mathrm{a}}$ & NA & - & - \\
\hline Dyspnoea & 25 & 29.8 & 18 & 26.5 & 7 & 43.8 & $0.174^{\mathrm{c}}$ \\
\hline Anosmia $^{a}$ & 17 & $35 \cdot 4^{a}$ & 17 & $35 \cdot 4^{a}$ & NA & - & - \\
\hline Asthenia & 19 & 22.6 & 16 & 23.5 & 3 & 18.7 & $1.000^{\mathrm{b}}$ \\
\hline Diarrhoea & 16 & 19.0 & 16 & $23 \cdot 5$ & 0 & 0.0 & - \\
\hline Myalgia/arthralgia & 10 & 11.9 & 9 & 13.2 & 1 & 6.3 & $0.679^{b}$ \\
\hline Sputum & 9 & 10.7 & 8 & 11.8 & 1 & 6.3 & $1.000^{\mathrm{b}}$ \\
\hline Headache & 7 & 8.3 & 7 & 10.3 & 0 & 0.0 & - \\
\hline Nausea/vomit & 7 & 8.3 & 7 & 10.3 & 0 & 0.0 & - \\
\hline Sore throat & 5 & 5.9 & 5 & $7 \cdot 3$ & 0 & 0.0 & - \\
\hline Nasal congestion & 4 & 4.8 & 4 & 5.8 & 0 & 0.0 & - \\
\hline Rash & 2 & 2.4 & 2 & 2.9 & 0 & 0.0 & - \\
\hline
\end{tabular}

COVID-19: coronavirus disease; ICU: intensive care unit; NA: not available.

a Available for 48 of 68 patients.

b Fisher's exact test.

' chi square test.

least one comorbidity of which hypertension, coronary heart disease, diabetes mellitus were most frequent, oncologic illness former or still, COPD, chronic renal failure, chronic hepatitis $B$ and cerebrovascular disease were also present in a notable number of patients. We observed that the limited number of cases for which information was available, self-reported olfactory and/or taste disorders in $35 \%$ and $54 \%$, which was higher compared with a recent Italian study [3]. It was not possible to precisely estimate if these symptoms preceded or followed those that prompted medical referral. However, anosmia and dysgeusia should be considered as possible clinical indication of COVID-19 and lead to further investigation including testing for infection with severe acute respiratory syndrome coronavirus 2 (SARS CoV-2) [4].

Comparing admission characteristics between ICU and non-ICU cases, we found that COPD and Horowitz index at the time of hospitalisation were associated with ICU transfer in our series of COVID-19 cases (Table 1). The median days from the onset of symptoms to nasal swab was shorter for cases transferred to ICU probably because of a more severe clinical picture. Concerning laboratory results, we noticed a difference at admission in C-reactive protein and IL- 6 levels between the two groups, leading us to speculate that those parameters could be early markers for ICU transfer* $[5,6]$.

The overall proportion of cases transferred to ICU described here is higher compared with a Chinese cohort [7]. However, in our preliminary analysis, we observed a $12 \%$ reduction in ICU transfer rate adjusted for comorbidities between the pre- and post- intervention period $(p=0.002)$. This benefit is represented by avoiding endotracheal intubation, taking out possible infectious risks. However, endotracheal intubation should not be delayed in patients with haemodynamic instability, multiorgan failure, or abnormal mental status [8]. Unfortunately, we could not now evaluate if the intervention had an impact also on mortality, because 19 (22.6\%) patients were still hospitalised, and mortality rate could have been underestimated in N-ICU. Current evidence against corticosteroid application in COVID-19 is unclear, but the Chinese Thoracic Society recently developed an expert consensus statement on the use of corticosteroids SARS-CoV-2 pneumonia [9]. The increase in corticosteroid prescriptions in the postintervention period could have played a role in reducing ICU transmission rate. Because of the small sample size and limited outcome information, we could not run a solid multivariable analysis and these results should be cautiously interpreted.

In conclusion, in this Italian cohort, the majority were men older than 60 years with at least one comorbidity in nearly $60 \%$. A self-reported anosmia and/or dysgeusia were frequent symptoms similar to what has been described in a recent European and Italian study $[3,4]$. The rising intensity of care seemed to reduce the ICU transfer rate and endotracheal intubation. The main limitation of this study is the small sample size analysed. 
Clinical characteristics at admission of COVID-19 cases hospitalised before and after the implementation of additional intensive care measures at the infectious and tropical diseases unit of University Hospital, Florence, Italy, 25 February-26 March $2020(\mathrm{n}=84)$

\begin{tabular}{|c|c|c|c|c|c|}
\hline \multirow[t]{2}{*}{ Clinical characteristics } & \multicolumn{2}{|c|}{$\begin{array}{l}\text { Before implementation } \\
\qquad n=31\end{array}$} & \multicolumn{2}{|c|}{$\begin{array}{l}\text { After implementation } \\
\qquad \mathrm{n}=53\end{array}$} & \multirow[t]{2}{*}{$p$ value } \\
\hline & $\mathrm{n}$ & $\%$ or (IQR) & $\mathrm{n}$ & $\%$ or (IQR) & \\
\hline \multicolumn{6}{|l|}{ Age and sex } \\
\hline Age, median (years) & 64 & $(58-72)$ & 59 & $(50-51)$ & $0.1822^{c}$ \\
\hline Male & 19 & 61.3 & 36 & 67.9 & \multirow{2}{*}{$0.537^{\mathrm{b}}$} \\
\hline Female & 12 & 38.7 & 17 & 32.1 & \\
\hline \multicolumn{6}{|l|}{ Smoking } \\
\hline Former smoker & 11 & 35.5 & 8 & 15.1 & \multirow{4}{*}{$0.100^{a}$} \\
\hline Smoker & 2 & & 4 & & \\
\hline Non-smoker & 16 & 51.6 & 30 & 56.6 & \\
\hline Missing & 2 & 6.5 & 11 & 20.7 & \\
\hline \multicolumn{6}{|l|}{ Underlying conditions } \\
\hline Diabetes mellitus & 8 & 25.8 & 4 & 7.6 & $0.028^{a}$ \\
\hline COPD & 2 & 6.5 & 3 & 5.7 & $1.000^{\mathrm{a}}$ \\
\hline Coronary heart disease & 5 & 16.1 & 7 & 13.2 & $0.712^{\mathrm{b}}$ \\
\hline Hypertension & 18 & 58.1 & 13 & 24.5 & $0.002^{\mathrm{b}}$ \\
\hline Chronic hepatitis B & 1 & 3.2 & 1 & 1.9 & $1.000^{\mathrm{a}}$ \\
\hline Cerebrovascular disease & 1 & 3.2 & 1 & 3.2 & $1.000^{\mathrm{a}}$ \\
\hline Former or still oncologic diseases & 3 & 9.7 & 4 & 7.6 & $0.705^{a}$ \\
\hline Chronic renal failure & 1 & 3.2 & 2 & 3.8 & $1.000^{\mathrm{a}}$ \\
\hline Horowitz index at the baseline, median & 306 & $(276-347)$ & 328 & $(295-366)$ & $0.1029^{c}$ \\
\hline $\begin{array}{l}\text { C-reactive Protein }(\mathrm{mg} / \mathrm{L}) \text {, median } \\
\text { (Norm: }<5 \mathrm{mg} / \mathrm{L} \text { ) }\end{array}$ & 50 & $(25-82)$ & 64 & $(17-133)$ & $0.4169^{c}$ \\
\hline
\end{tabular}

COPD: chronic obstructive pulmonary disease; COVID-19: coronavirus disease; IQR: interquartile range.

a Fisher's exact test.

${ }^{\mathrm{b}}$ chi square test.

c Kruskal-Wallis test.

\section{* Authors' correction}

Upon the authors' request, the following corrections were made on 11 May 2020, after publication of the article: the number of patients discharged at the cut-off date was corrected. Furthermore, in Table 1, numbers for 'High Flow with Nasal Cannula >24h' were corrected and under 'Clinical and laboratory characteristics', the number of patients for whom information on IL-6 (pg/ $\mathrm{mL}$ ) results was available was wrong in the text and in Table 2 and corrected. The corrections referring to IL-6 $(\mathrm{pg} / \mathrm{mL})$ serum levels resulted in a statistically significant difference, where there was no difference in the original publication, between 'Not ICU transferred' and 'ICU transferred' patients. Consequently, one of the conclusions was changed from 'Concerning laboratory results, we did NOT notice any difference at admission in IL-6 levels between the two groups, leading us to speculate that the included patients were in an early stage of the disease and IL- 6 production might be triggered in the later stages only [5,6].' to 'Concerning laboratory results, we noticed a difference at admission in C-reactive protein and IL-6 levels between the two groups, leading us to speculate that those parameters could be early markers for ICU transfer $[5,6]$.' Together with these corrections, footnotes were added to Tables 1,2 and 4 to indicate variables for which Kruskal-Wallis test was applied.

The authors apologise for the inconvenience.

COCORA working group members not listed as individual author

Irene Campolmi, Nicoletta Di Lauria, Giovanni Millotti, Gregorio Basile, Massimo Meli, Pier Giorgio Rogasi, Dario Bartolozzi, Paola Corsi, Marcello Mazzetti, Alberto Farese, Silvia Bresci, Annalisa Cavallo, Michele Trotta, Giampaolo Corti, Alessandro Morettini, Loredana Poggesi, Angelo Raffaele De Gaudio, Adriano Peris, Paolo Fontanari, Paola Parronchi, Fabio Almerigogna, Francesco Annunziato, Francesco Liotta, Lorenzo Cosmi, Alessandra Vultaggio, Andrea Matucci, Manuela Angileri, Alessandra Ipponi, Michele Cecchi, Silvia Benemei, Alessandro Maria Vannucchi, Marco Matucci-Cerinic, Lucia Turco. 


\section{Acknowledgements}

Funding statement: This article has been supported by funds of "Ministry of Education, University and Research (Italy) Excellence Departments 2018-2022" Project for the Department of Experimental and Clinical Medicine.

The authors thanks Lucia Sammicheli, Giulia Guazzini, Carlo Caresia, Annamaria Durval, Sasha Damiani, Maria Cristina Maggioni, Viviana Marcellino, Mauro Evangelisti, Tommaso Borracci, Ilaria Guerri, Simona Biondi, Manuela Bonizzoli for collaborating in the management of patients.

\section{Conflict of interest}

None declared.

\section{Authors' contributions}

Study conceptualisation: Filippo Lagi, Jessica Mencarini, Matteo Piccica, Lorenzo Zammarchi, Alessandro Bartoloni.

Data collection: Filippo Lagi, Jessica Mencarini, Irene Campolmi, Annarita Botta, Nicoletta Di Lauria, Matteo Piccica, Lucia Graziani, Iacopo Vellere, Marta Tilli, Giovanni Millotti, Letizia Ottino, Gregorio Basile.

Data elaboration and interpretation: Filippo Lagi, Jessica Mencarini, Lorenzo Zammarchi, Alessandro Bartoloni.

Manuscript writing: Filippo Lagi, Lorenzo Zammarchi, Alessandro Bartoloni.

Patients management and manuscript reviewing: Filippo Lagi, Jessica Mencarini, Annarita Botta, Matteo Piccica, Lucia Graziani, lacopo Vellere, Marta Tilli, Giovanni Millotti, Letizia Ottino, Beatrice Borchi, Marco Pozzi, Filippo Bartalesi, Michele Spinicci, Lorenzo Zammarchi, Nicoletta Di Lauria, Lucia Graziani, Giovanni Millotti, Gregorio Basile, Massimo Meli, Pier Giorgio Rogasi, Dario Bartolozzi, Paola Corsi, Marcello Mazzetti, Alberto Farese, Silvia Bresci, Michele Trotta, Giampaolo Corti, Annalisa Cavallo, Filippo Pieralli, Carlo Nozzoli, Giovanni Zagli, Stefano Romagnoli, Alessandro Morettini, Loredana Poggesi, Paolo Fontanari, Paola Parronchi, Fabio Almerigogna, Francesco Liotta, Lorenzo Cosmi, Alessandra Vultaggio, Andrea Matucci, Manuela Angileri, Alessandra Ipponi, Michele Cecchi, Alessandro Maria Vannucchi.

Project supervision and manuscript reviewing: Francesco Annunziato, Alessandro Bartoloni, Angelo Raffaele De Gaudio, Carlo Nozzoli, Adriano Peris, Lucia Turco, Silvia Benemei, Michele Cecchi, Marco Matucci-Cerinic.

\section{References}

1. Onder G, Rezza G, Brusaferro S. Case-fatality rate and characteristics of patients dying in relation to COVID-19 in Italy. JAMA. 2020;2019:2019-20. https://doi.org/10.1001/ jama.2020.4683 PMID: 32203977

2. World Health Organization (WHO). Coronavirus disease 2019 (COVID-19). Situation report - 98. Geneva: WHO; 2020. Available from: https://www.who.int/docs/default-source/ coronaviruse/situation-reports/20200427-sitrep-98-covid-19. pdf?sfvrsn=90323472_4

3. Giacomelli A, Pezzati L, Conti F, Bernacchia D, Siano M, Oreni $L$, et al. Self-reported olfactory and taste disorders in SARS CoV-2 patients: a cross-sectional study. Clin Infect Dis. 2020; ciaa330: Epub ahead of print.

4. Lechien JR, Chiesa-Estomba CM, De Siati DR, Horoi M, Le Bon $\mathrm{SD}$, Rodriguez A, et al. Olfactory and gustatory dysfunctions as a clinical presentation of mild-to-moderate forms of the coronavirus disease (COVID-19): a multicenter European study. Eur Arch Otorhinolaryngol. 2020. https://doi.org/10.1007/ s00405-020-05965-1 PMID: 32253535

5. Lin L, Lu L, Cao W, Li T. Hypothesis for potential pathogenesis of SARS-CoV-2 infection-a review of immune changes in patients with viral pneumonia. Emerg Microbes Infect. 2020;9(1):727-32. https://doi.org/10.1080/22221751.2020.174 6199 PMID: 32196410

6. Mehta P, McAuley DF, Brown M, Sanchez E, Tattersall RS, Manson JJHLH Across Speciality Collaboration, UK. COVID-19: consider cytokine storm syndromes and immunosuppression. Lancet. 2020;395(10229):1033-4. https://doi.org/10.1016/ So140-6736(20)30628-0 PMID: 32192578

7. Guan W-I, Ni Z-Y, Hu Y, Liang W-H, Ou C-Q, He I-X, et al. Clinical characteristics of coronavirus disease 2019 in China. N Engl J Med. 2020; NEJMoa2002032: Epub ahead of print. PMID: 32109013

8. World Health Organization (WHO). Clinical management of severe acute respiratory infection (SARI) when COVID-19 disease is suspected. Interim guidance V 1.2. Geneva: WHO; 13 Mar 2020.Available from: https://www.who.int/ publications-detail/clinical-management-of-severe-acuterespiratory-infection-when-novel-coronavirus-(ncov)-infectionis-suspected

9. Shang L, Zhao J, Hu Y, Du R, Cao B. On the use of corticosteroids for 2019-nCoV pneumonia. Lancet. 2020;395(10225):683-4. https://doi.org/10.1016/S01406736(20)30361-5 PMID: 32122468

\section{License, supplementary material and copyright}

This is an open-access article distributed under the terms of the Creative Commons Attribution (CC BY 4.0) Licence. You may share and adapt the material, but must give appropriate credit to the source, provide a link to the licence and indicate if changes were made.

Any supplementary material referenced in the article can be found in the online version.

This article is copyright of the authors or their affiliated institutions, 2020. 